\title{
MULTICRITERION ANALYSIS AND CHOOSING OF THE OPTIMAL ROUTING IN AD-HOC NETWORKS
}

\author{
Valeriy Bezruk, Kyrylo Halchenko \\ Kharkiv National University of Radioelectronics, Department "Information and Network Engineering"
}

Abstract. The paper discusses the practical aspects of application of multicriterion approach to solving the problem of an optimal routing for wireless selforganizing networks. As the initial metrics analyzed convergence time, memory overhead, control overhead, time complexity and communication complexity.

Keywords. ad-hoc network, routing protocols, optimization

\section{ANALIZA WIELOKRYTERIALNA I WYBÓR OPTYMALNEJ TRASY ROUTINGU W SIECIACH AD-HOC}

\begin{abstract}
Streszczenie. W artykule omówiono praktyczne aspekty zastosowania podejścia wielokryterialnego do rozwiąania problemu optymalnego trasowania dla bezprzewodowych samoorganizujących się sieci. Jako początkowe metryki analizowano czas zbieżności, narzut pamięci, narzut sterowania, złożoność czasu i złożoność komunikacji.
\end{abstract}

Słowa kluczowe: sieci ad-hoc, protokoły routing, optymalizacja

\section{Introduction}

Ad-hoc network is a network of self-sustaining, without using a single access point [4]. When creating such networks do not develop any map location of their deployment and previous plans because they are usually small and have limited long enough for the transfer of shared data in the event of such need. Also standard is not limited to the number of devices that may be included in an independent basic service area. Ad-hoc structure is suitable for the rapid deployment of networks. This mode requires minimal equipment: each station must be equipped with a wireless adapter. With this configuration, no need to create network infrastructure. The main disadvantages of ad-hoc mode are limited to the range of the network, limitations imposed on the power devices and the problem of routing with substantial mobility of nodes.

The routing protocols can be classified into three groups: global/proactive, on-demand, reactive and hybrid [1, 5, 7]. In proactive routing protocols the routes to all the destination (or parts of the network) are determined at the start up, and maintained by using a periodic route update process. In reactive protocols routes are determined, when they are required by the source using a route discovery process. Hybrid routing protocols combine the basic properties of the first two classes of protocols into one. That is they are both reactive and proactive in nature.

The large number of routing protocols specific to these networks is an urgent task of choosing the of optimal protocols with using the set of objective quality indicators. They are determined by basic metrics such as convergence time, memory overhead, control overhead, time complexity and communication complexity. The important task also is a choice of the optimal routes in network with using the set of objective quality indicators $[2,3]$.

It determines the necessity of the use for this purpose methods of multicriterion optimization. Thus, actual are researches of features of application of methods of multicriterion optimization at the decision of tasks of routing in ad-hoc networks. Therefore in this work for solution these tasks it is proposed to use the methods of multicriterion optimization in ad-hoc networks.

In addition, due to the increase in computing capabilities of devices used in Mesh networks, it is possible to implement individual smart protocols and routing methods in self-organizing networks. Firstly, most of advantages multicriteria optimization methods are already used in MANET, but earlier there was increased use of resources of the mesh, due to use compromise complex [6].

\section{Choosing of the optimal variants system by multicriteria optimization methods}

Let's consider the basic features of a choice of optimum variants of the routing systems with use of methods of multicriterion optimization. Suppose that the system is characterized by a set of objective quality indicators

$$
\vec{k}(\phi)=\left(k_{1}(\phi), . k_{2}(\phi), \ldots, k_{m}(\phi)\right)
$$

They determines the influence of the structure $s$ and the parameters vector $\beta$ of the variant of the system $\phi=(s, \vec{b})$ upon the system quality indicators. Each variant of the system $\phi$ is mapped from a set of permissible variants $\Phi_{d}$ into the criteria space of estimates $V \in R^{m}$ :

$$
V=\vec{K}\left(\Phi_{d}\right)=\left\{\vec{v} \in R^{m} \mid \vec{v}=\vec{k}(\phi), \phi \in \Phi_{D}\right\} .
$$

In this case to each approach $\phi$ corresponds its particular estimate of the selected quality indicators (1) and, vice versa, to each estimate corresponds an approach. When one can only attain the consistent optimum of introduced objective functions - the optimum according to the Pareto criteria, which implies that each of the indicators can be further improved singly by lowering the remaining quality indicators of the system.

To the Pareto optimum in the criteria space corresponds a set of Pareto-optimal estimates that satisfy the following expression $[5,6]$ :

$$
P(V)=o p t_{\geq} V=\left\{\vec{k}\left(\phi^{0}\right) \in R^{m} \mid \forall \vec{k}(\phi) \in V: \vec{k}(\phi) \geq \vec{k}\left(\phi^{0}\right)\right\} .
$$

An optimum based on the Pareto criteria can be found either directly according to (2) by the exhaustive search of all permissible variants of the system $\Phi_{D}$ or with the use of special procedures such as the weighting method, methods of operating characteristics. In these methods the decision of the task of multicriterion optimization is taken to some great number of tasks of scalar optimization.

Found of the Pareto-optimal routing protocols and optimal subset routes at the ad-hoc networks has important properties. In choosing the Pareto-optimal variant are eliminated by far the worst routing protocols options for an unconditional preference criterion. Moreover, Pareto-optimal variant of the routing corresponding to the agreed quality indicators introduced optimum (private functions). It means that the extreme value is reached for each of the quality metrics, which may be achieved without deterioration in the quality values of other parameters. 
Pareto-optimal routing protocols options, not comparable with each other and therefore are equivalent in terms of the Pareto criterion. Therefore, each of them may be used in solving special problems of routing based on a minimum power input devices, a minimum of overhead information or complexity of the algorithm that will uniformly load the link corresponding to the traffic types of the required quality of service. If there is the need for a single selection routing, this may be applied different methods of narrowing down to a single subset of Pareto options. This methods base on the value functions, the lexicographical approach, theory of fuzzy sets and other [2, 3]. In this methods the additional information is used from the experience experts.

The process of choosing optimal variants of routing includes such stages: setting the initial set of the system variants; separation of the permissible set of variants with regard of limitations on the network structure and parameters, limitation on the value of the quality indicators; choice of the subset of Pareto-optimal variants; choice of a single variant. The choosing of optimal design solutions by multicriterion optimization methods was implemented in a software package, based on Java.

It is not difficult to see that they correspond to the agreed optimum Pareto quality indicators (the minimum possible values of one quality indicator at a given fixed values of another indicator). This boundary is also a chart of the exchange of quality indicators, which shows how the potentially achievable value of one of the quality indicators depends on the value of another indicator.

The resulting subset of Pareto-optimal route variants can be used to organize multi-path routing and to select the optimal routes for transmitting the appropriate traffic with the required quality of service.

This raises the question: does it make sense to make a choice based on the unconditional criterion of preference (Pareto criterion), when further to choose a single route when faced to introduce conditional preference criterion. In justification of expediency of introduction of a stage of Pareto-optimal variants finding it is necessary to note:

- the use of the unconditional criterion of preference (UCP) makes it possible to find all Pareto-optimal routes, while discarding all certainly the worst route options,

- the use of UCP makes it possible to find the best possible values of each of the indicators of quality and the relationship between them,

- even if when choosing a single route option you have to enter a conditional preference criterion, it is better to enter all sorts of skills at a later stage of selection.

Methodology of choosing of the optimal of the routing protocols and optimal routes by multicriterion optimization methods was used for the decision of the different tasks of the designing in the area telecommunications taking into account totality of quality indicators. It is tasks of choice of optimal speech codecs and optimal types of modulation in the telecommunications systems, optimal structure and parameters of radio networks and transport networks and also radiotechnologies in mobile communication networks.

\section{Consider given methods in routing process}

Practical features of the solution of the specified multicriterion routing problem are considered using the example of a fragment of the communication network (Fig. 1).

The model of the network under investigation consists of twelve nodes linked by lossy communication [3]. We will consider the following quality on line:

- packet delay time,

- the level of packet of service indicators, which characterize each communication loss,

- cost of using the communication line.
We will assume that the packet delay time is determined mainly by the length of the communication lines. The level of packet loss depends on the loss model introduced in each line. The cost of using the line depends on the delay time on the line, the amount of loss and intensity of use. The research was conducted in the Network Simulator software package.

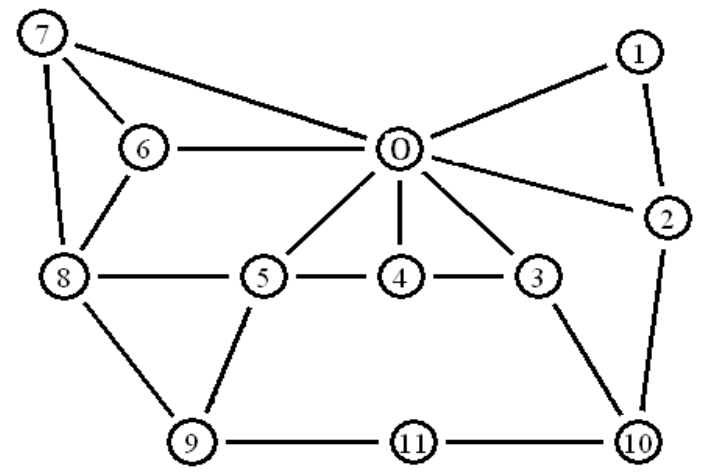

Fig. 1. The example of a fragment of the communication network

For description of investigated network and choice of optimal variant of routing the mathematical model was used in a kind $\{X, F\} \rightarrow x^{*}$ [7]. Here $X=\{x\}-$ set of routes on the network graph $G=(V, E) ; F(x)$ - objective function of choice of the routes; $x^{*}-$ optimal variant of the routing.

In case of the multicriteria approach to the choosing of the optimal routes on the set $X$ it is given the vector of the objective function:

$$
\vec{F}(x)=\left(F_{1}(x), \ldots F_{j}(x), \ldots F_{m}(x)\right)
$$

Components of this function determine the values of quality routes indicators. The variant of the route $x^{*} \in X$ is Paretooptimal route if another route $x \in X$ doesn't exist, order to perform inequality $F_{j}\left(x^{*}\right) \leq F_{j}(\tilde{x}), j=1, \ldots, m$, where at least one of the inequalities is strict [4]. When selecting a subset of the Paretooptimal routes there was dropped a certainly worst variant in terms of the absolute criteria of preference. Pareto-optimal alternatives of the routes are equivalent to the Pareto criteria and could be used for organizing multipath routing in the multi-service telecommunication networks.

Network analysis shows that for each destination node there are many options to choose the route directly. These variants are presented in the criteria space of the two quality indicators $-\mathrm{k}_{1}$ (delay time of packets transmission) and $\mathrm{k}_{2}$ (the level of packets loss) (Fig. 2). Subset of the Pareto-optimal alternatives routes corresponds to the left lower border which includes three variants; they are marked $(\boldsymbol{\Lambda})$.

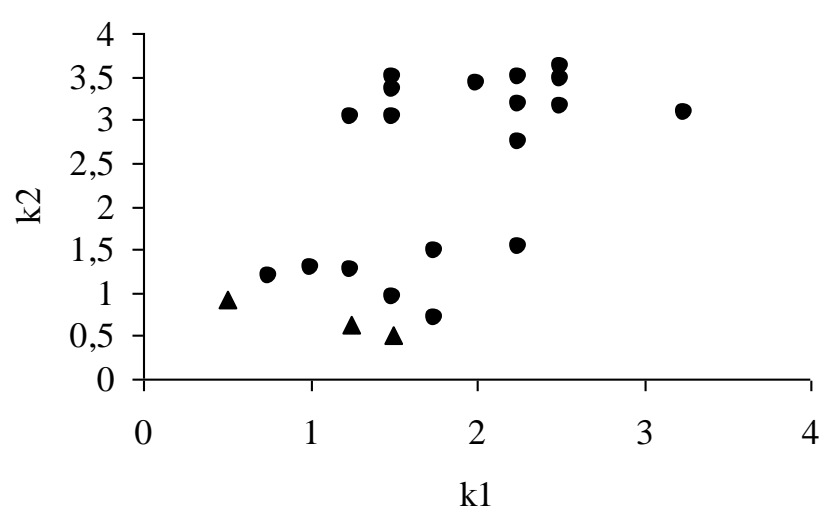

Fig. 2. Presenting of the variants of the routes in the criterial space of the two quality indicators 
The resulting Pareto-optimal alternative routes can be used for organizing multipath routing in ad-hoc networks when using MPLS technology. It will allow to provide a load balancing and a traffic management and to provide given quality-of-service taking into account the set of the quality indicators.

Various methods based on attraction of some additional subjective information in the form of experts' judgments can be used for narrowing the Pareto set to the unique design solution. Theoretical and practical aspects of choosing the preferable version of routing protocols taking into account the totality of quality indices and experts' judgments based on hierarchical analysis method are considered. Scientific novelty of work consists in the application of hierarchy analysis method for comparative analysis and selection of a preferred version of routing protocols taking into account a set of indicators of quality and judgments of experts [3].

The hierarchical analysis method consists in decomposition of the problem of choosing a single project variant of a certain system for several levels and obtaining expert judgments on pair comparisons of various elements of the choice problem. As a result of processing the obtained numerical data according to a certain mathematical procedure receive components of the global priority vector that characterize the priority of choosing the versions of the projected system and determine the choice of the preferred design variant of the system.

The principle of comparative judgments of experts in the hierarchical analysis method is that the objects of the choice problem are compared by experts in pairs in importance, in particular, the system variants and quality indicators are compared. Estimates of paired comparisons of elements are found using subjective judgments of experts on the scale of relative importance of the elements. The results of paired comparisons are reduced to the matrix form. Next, the matrices of paired comparisons of different elements of the hierarchy are processed. From the mathematical point of view, this processing task is reduced to the calculation of the main eigenvector of the matrix of paired comparisons, which after normalization becomes the priority vector of the elements at the corresponding hierarchy level.

Matrixes of pair comparisons of system variants are found separately in relation to each indicator of system quality. On the basis of these matrices, the components of the corresponding main eigenvectors and priority vectors are calculated with respect to the quality indicators. Using this data, the values of the components of the global priority vector are calculated. The preferred version of the system is selected for the maximum value of the global priority vector components.

An example of choosing the preferred routing protocol from the set of existing variants of routing protocols taking into account three quality indicators is considered. Matrixes of pair comparisons of routing protocol variants are found separately in relation to each indicator of quality. On the basis of these matrices, the components of the corresponding main eigenvectors and priority vectors are calculated with respect to the quality indicators. Using this data, the values of the components of the global priority vector are calculated. The preferred version of the routing protocol is selected for the maximum value of the global priority vector components.

The comparison of the routing options routing according to the known OSPF Protocol. In the existing algorithm OSPF dynamic routing Protocol status (quality route) is defined by three characteristics: latency, throughput and reliability. However, only one of the quality metrics is selected and used for routing.

We illustrate the proposed multi-criteria approach to route selection and the approach to route selection based on the OSPF Protocol.
When using the multi-criteria approach, the set of Paretooptimal routes, which is used in the organization of multi-path routing, the load lines are more uniform, there are no large overloads on individual communication lines, unlike OSPF routing. As a result, there is a gain of a multicriteria approach when taking into account the losses of packets and the cost of using communication lines with respect to the OSPF Protocol. Although OSPF will win in terms of a time delay, as he had chosen the path of only one indicator of quality.

The use of a variety of Pareto-optimal route options creates a more uniform load of lines, in addition, each route takes into account all the quality indicators and is the agreed optimum. Figure 3 shows that the multi-criteria approach takes into account and optimizes (minimizes) all quality indicators equally in a compromise (uniform) consideration of the importance of all quality indicators.

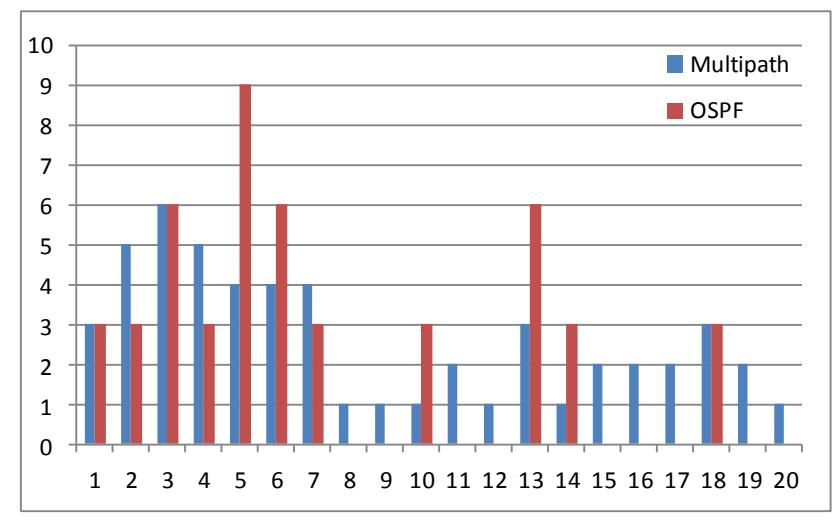

Fig. 3. The load of the lines using a set of Pareto-optimal routes (multipath routing) and $O S P F$ routes

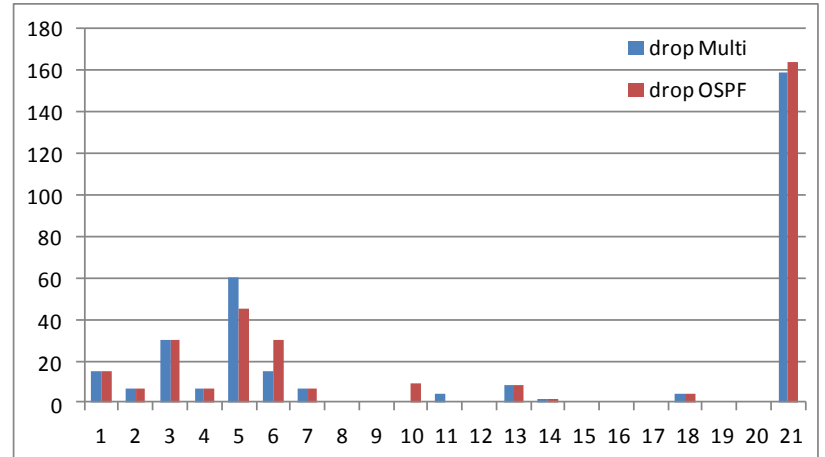

Fig. 4. Comparison of the multicriteria approach with the importance factors $(0.3 ; 0.3 ; 0.4)$ and the OSPF Protocol for the packet loss on those routes

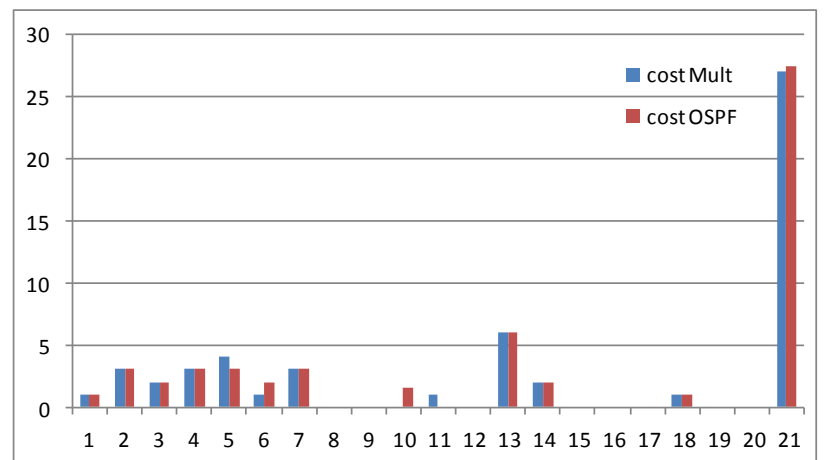

Fig. 5. Comparison of the multicriteria approach with the importance factors $(0.3 ; 0.3 ; 0.4)$ and the OSPF Protocol for the cost of the selected routes 

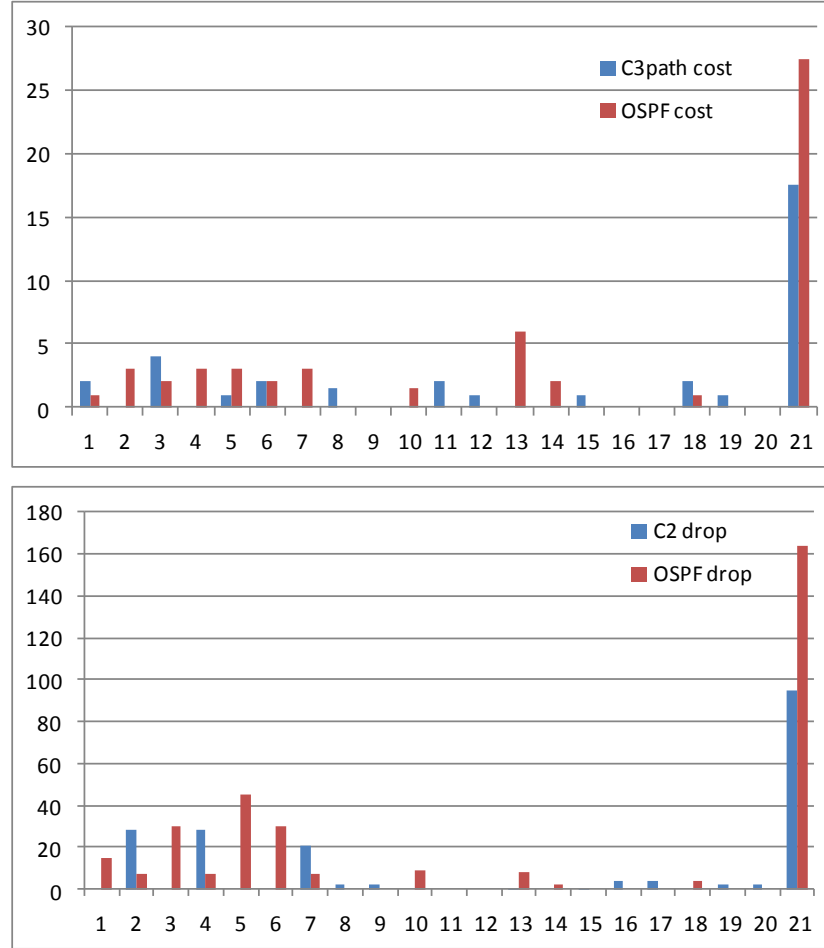

Fig. 6. Shows a comparison of the multicriteria approach with the importance coefficients $(0.1 ; 0.1 ; 0.8),(0.1 ; 0.8 ; 0.1)$ and OSPF Protocol on the cost of selected routes and packet loss on these routes

With the introduction of conditional preference criterion, that is, the allocation of a more important quality indicator, relative to other possible from the set of Pareto- optimality routes to select a single option. When allocating from the point of view of the importance of a quality indicator, reflecting the cost of use of communication lines, are the routes corresponding to the coefficients of importance $(0.1 ; 0.1 ; 0.8)$. When allocating from the point of view of the importance of quality score, reflecting the level of losses of packets are received routes that match the coefficients of importance $(0.1 ; 0.8 ; 0.1)$.

\section{Conclusions}

1) Review of the existing routing protocols in ad-hoc networks is performed.

2) Methodology of choosing of the optimal of the routing protocols and optimal routes by the multicriteria optimization methods is obtained.

3) Software package for the multicriterion choice of optimal design decisions are proposed.
4) Results of the comparative analysis of the existing routing protocols based on the proposed methodology are discussed.

5) Practical features of the solution of the multicriteria routing problem are considered.

6) Pareto-optimal alternative routes can be used for the organizing multipath routing at the ad-hoc networks.

7) Examples of the problems of choice of the preferred version for different types of routing protocols are considered.

8) In comparsion with OSPF detected strong efficiency in lines loading on Pareto-optimal multicriteria routes.

\section{References}

[1] Abolhasan M., Wysocki T., Dutkiewicz E.: A review of routing protocols for mobile ad hoc networks. Ad Hoc Networks 2/2004, 1-22.

[2] Bezruk V, Bukhanko A. et al.: Multicriterion optimization in telecommunication networks planning, designing and controlling. Open Book «Telecommunications Networks: Current Status and Future Trends». Rijeka: INTECH, 2012, 251-274.

[3] Bezruk V., Chebotaryova D., Skoryk Y.: Multicriterion analysis and choice analys optimization of the telecommunication means. SMIT, Kharkov 2017.

[4] Cordeiro C., Agrawal D.: Ad hoc and sensor networks. Theory and Applications. World Scientific, Singapore 2006.

[5] Dube R., Rais C., Wang K., Tripathi S: Signal stability-based adaptive routing (SSA) for ad hoc mobile networks. IEEE Pers. Commun.4/1998, 36-45.

[6] Parissidis G., Lenders V., May M., Plattner B: Multi-path Routing Protocols in Wireless Mobile Ad Hoc Networks: A Quantitative Comparison. Swiss Federal Institute of Technology Communications Systems Group, Zurich 2006.

[7] Toh C.-K.: Associative-based routing for ad hoc mobile networks. Wireless Personal Communications Journal, Special Issue on Mobile Networking and Computing Systems 4(2)/1997, 103-139.

\section{Prof. Valeriy Bezruk \\ e-mail: valerii.bezruk@nure.ua \\ Graduated from Kharkiv Institute of Radio Electronics, Ukraine (major "Radio engineering") in 1973. In 2004 he received the degree of Doctor of Technology and in 2005 he obtained the academic rank of professor. In 2009 he was elected as the head of Communication Networks department of Kharkiv National University of Radio Electronics. Scientific interests: signal recognition, probability modeling and multicriteria optimization of systems.}

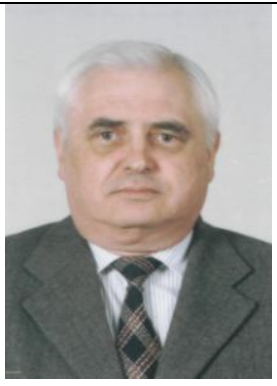

M.Sc. Kirill Halchenko

e-mail: kyrylo.halchenko@nure.ua

Graduated from Kharkiv National University of Radio Electronics, Ukraine (major "Informational Comunication Networks") in 2015. From 2015 Postgraduate of Kharkiv National University of Radio Electronics. Scientific interests: network routing services, automated program interfaces services.

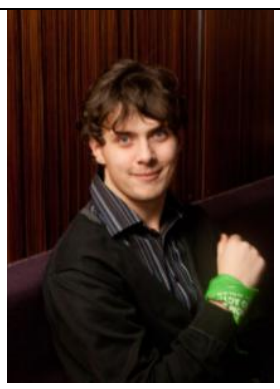

otrzymano/received: 15.03 .2018 przyjęto do druku/accepted: 15.09 .2018 